\title{
Conceptual Labs for operative Exploration
}

\author{
Marisa Michelini' \\ Research Unit in Physics Education, DCFA, University of Udine \\ via delle Scienze 206, 33100 Udine, Italy \\ E-mail: marisa.michelini@uniud.it
}

\section{Lorenzo Santi, Alberto Stefanel}

Research Unit in Physics Education, DCFA, University of Udine

via delle Scienze 206, 33100 Udine, Italy

E-mail:Iorenzo.santiluniud.it, alberto.stefanelauniud.it

In the perspective of the Model of Educational Reconstruction, designing new educational path require to gain new information on how students face the specific subject explored. At the PERG of Udine the main steps of the new educational paths were explored with pupils engaged in Conceptual Laboratory of Operative Exploration (CLOE) in informal learning contexts, where using different monitoring tools student spontaneous ideas as well their learning paths were explored and stimulated. In CLOE pupils discuss everyday life scenarios, recover their everyday and sensorial knowledge, as well as involve them in the challenges of explorations according to an IBL strategies. The CLOE lab are research based proposals of learning where explore how pupils build formal thinking, reflect on phenomena and construct models, reinterpret common everyday knowledge. The research focus is on the reasoning sequence, the ways in which knowledge is structured, the development of interpretative representations. The design characteristic of the CLOE labs are presented exemplifying it in the case of the CLOE on energy.

Frontiers of Fundamental Physics 14

FFP14

15-18 July 2014

Aix Marseille University (AMU) Saint-Charles Campus, Marseille

\section{${ }^{1}$ Speaker}




\section{Introduction}

The concept of energy at any level has a central role in the whole science curricula, being a synthetic way to look at the phenomena and a conceptual organizer in their analysis [1-3] and therefore an important part of the cultural baggage for all citizens [3-6]. A great effort was made in the last two decades of the past century to propose hands on/minds on approaches to the concept of energy in middle school [4-9], and to study on how students construct their energy based view on the phenomena [7-14]. For the primary school level, some proposals show that it is possible to implement an operative qualitative approach to energy with students of 4-5th grade [15-17]. In spite of this, many open research questions remain: approaches to be followed, conceptual knots to be considered, at what age to introduce it, how to bridge the gap between the scientific meaning of energy with that of everyday life usage, of the word, energy [2-4, 19].

In a research project about teaching and learning energy in a vertical perspective, we have had designed and experimented an inquiry based educational approach for primary students in a school. This approach was the base for an informal learning activity implemented as Conceptual Laboratories of Operative Exploration (CLOE) [20-22]. The CLOE labs constitute, in our project, a research environment to test, from one side, the crucial knots of our proposal, to explore, on the other side, the students' learning path, using audio-records, questionnaires, stimuli open worksheets. The structure as research educational environment of the CLOE labs on energy will be presented, discussing the students learning processes analyzed.

\section{The CLOE labs: informal learning context for research}

The CLOE labs were designed as research context since 2001 [20-22]. The CLOE Labs on energy, considered here, were proposed to the primary schools of Udine and Crema (Italy), involving 310 students (7-10 years old), in inquiry based labs [22]. as presented in table 1 .

TABLE I. Students, classes, schools involved in the CLOE Labs on energy in Udine and Crema

\begin{tabular}{|c|c|c|c|c|c|}
\hline \multirow{2}{*}{ Year } & \multirow{2}{*}{ Place } & \multicolumn{4}{l|}{ N students $($ N classes) } \\
\cline { 3 - 6 } & & 2 grade & 3 grade & 4 grade & 5 grade \\
\hline 2008 & Udine & & $14(1)$ & $62(4)$ & $98(6)$ \\
\hline 2009 & Udine & & $30(2)$ & & $30(2)$ \\
\hline 2009 & Crema & & $7(1)$ & $28(1)$ & $78(6)$ \\
\hline 2011 & Udine & $63(3)$ & $33(2)$ & $22(1)$ & $104(6)$ \\
\hline & Total & $63(3)$ & $84(6)$ & $112(6)$ & $310(20)$ \\
\hline
\end{tabular}

Each CLOE lab lasted 90 minutes and was divided in three phases. 1) Students filled individually a written questionnaire (see Table II). 2) They discussed in large group the written answers, to individuate the problematic points, to share the suggested situations useful as starting points of the $3^{\text {rd }}$ phase. 3) A researcher proposed to little groups of four or five pupils a sequence of simple experiments, followings their conceptual path, suggestion, question.

The second phase, was conducted using semi-structured interviews with multi-interventions and audio-registrations. In the third phase, along with the audio-registration, students used the following instruments according to the specific aim of the lab: C1) Inquiry Base Learning stimuli worksheets based on a Prevision, Experiment, Comparison cycle [20. 22] 21, 24], to monitor crucial passage of the educational path; C2) worksheets, to collect the representations and description in term of energy of explored situations; C3) open cards to resume the activities, 
collecting "what was done", "what has been observed", "conclusions were reached". The student's ideas and reasoning evolution are analysed to answer to the following research questions: RQ1. Student's angle of approach to the concept of energy, which are the issues, systems and contexts students associate prevalently to energy? RQ2. Energy sources, transformation, conservation, storage, loss, meanings: what are the meanings that students attribute to the expressions such as conserve, transform, loss of energy? RQ3. In which way the stimulus situations such as hands-on/minds-on are proposed such that they contribute to a scientific vision of energy?

TABLE II. Questions posed to the students in the interview opening a CLOE lab on energy and the aspects analyzed in the answers of each question.

\begin{tabular}{|l|l|}
\hline Question & Research questions/goals of the inquiry \\
\hline $\begin{array}{l}\text { Q1. What do you know about } \\
\text { Energy? }\end{array}$ & $\begin{array}{l}\text { - way of spontaneous identification of energy, and situations } \\
\text { recalling energy process; properties attributed to energy; en- } \\
\text { ergy forms/types quoted }\end{array}$ \\
\hline $\begin{array}{l}\text { Q2. As far as you know, are } \\
\text { there things that make energy? }\end{array}$ & $\begin{array}{l}\text { - collect ideas on sources (is the prevailing one) } \\
\text { - meaning of making energy = produce or create or transform) }\end{array}$ \\
\hline $\begin{array}{l}\text { Q3. As far as you know, are } \\
\text { there things that have/possess } \\
\text { energy? }\end{array}$ & $\begin{array}{l}\text { - spontaneous association of possessing energy and list of } \\
\text { cases mentioned (extension of idea of "posses", for pupils); } \\
\text { - have pupils the idea of state property, or material types? }\end{array}$ \\
\hline $\begin{array}{l}\text { Q4. Is energy conserved? In } \\
\text { your answer explain what is } \\
\text { meant by conserved. }\end{array}$ & $\begin{array}{l}\text { - meaning of conservation } \\
\text { - examples mentioned for conservation } \\
\text { - way to associate conservation and transformation }\end{array}$ \\
\hline $\begin{array}{l}\text { Q5.Can energy be trans- } \\
\text { formed? Explain, giving two } \\
\text { examples }\end{array}$ & $\begin{array}{l}\text { - meaning of transformation } \\
\text { - collection of pupils examples }\end{array}$ \\
\hline $\begin{array}{l}\text { Q6. Can energy be lost? Ex- } \\
\text { plain giving 2 examples }\end{array}$ & $\begin{array}{l}\text { - meaning of energy losing and or dispersion } \\
\text { - list of examples familiar to pupils }\end{array}$ \\
\hline $\begin{array}{l}\text { Q7. What types of energy do } \\
\text { you know about? }\end{array}$ & $\begin{array}{l}\text { - types of energy quoted } \\
\text { - comparison with answers in Q1 }\end{array}$ \\
\hline
\end{tabular}

\section{The conceptual knots explored in the CLOE lab on energy}

The educational path at the base of the CLOE lab focus on the discussion of simple selected explorative situations, introducing step by step the different types of energy (kinetic, potential, internal and associated to light) and energy transformation, energy as property of state of systems [15]. The main goal is the construction of a language based on an energy point of view in processes, bridging from a common sense way, to a scientific way, to look at, the energy concept.
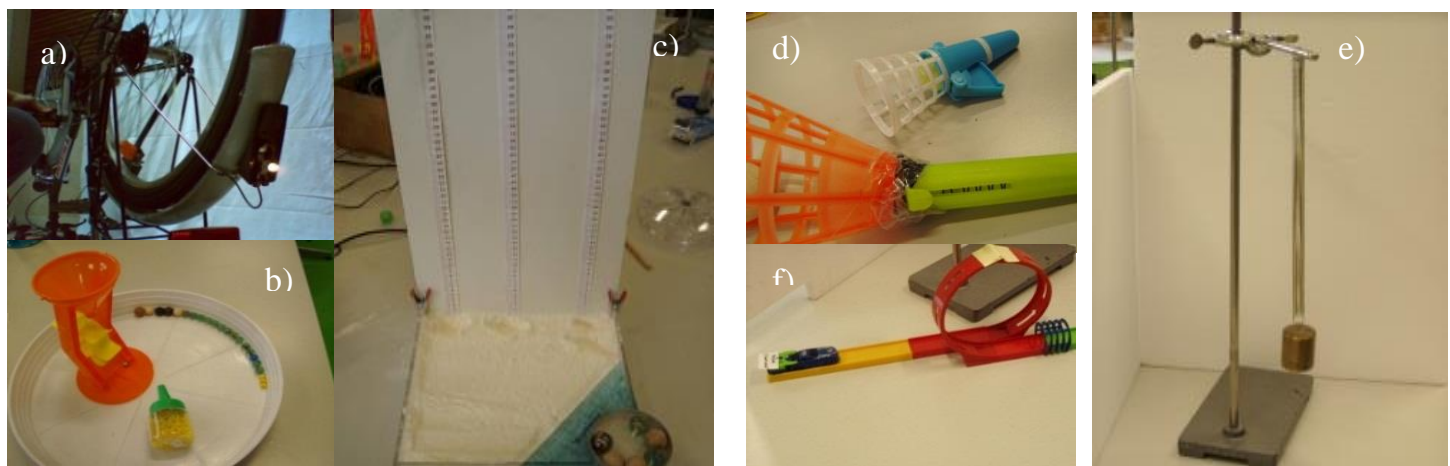

FIGURE 1. a) The upturned bicycle and b) the sand-mill toy as energy transform machines; c) the flour 
plane to explore the variables of potential energy; transformations involving elastic potential energy with d) a projectile spring launcher, e) a spring-mass and f) a toy car track

In the CLOE labs the driver follows the pupils' conceptual evolution. Simple apparatuses, realized with toys or everyday materials (Fig. 1) are proposed to students, focalizing on how they recognize the interaction underlying each energy transformation and the types of energy involved.

\section{Methodology}

According to the criteria of qualitative research [16], the answers to the open questions were analyzed, according to the a-priori research questions of table II, constructing an a-posteriori categorization of actual answers for what concern: A) examples quoted, to identify the extension of the meaning of the energy concept from different perspectives; B) ways in which energy is identified; C) properties that are attributed to energy; D) meaning attributed to expressions such as conserve, transform, loss of energy. The frequencies for each category are then crossed with data obtained from the successive audio-recorded discussion. In the second phase of the CLOE labs, in which students explore specific situations, the transcriptions of the audio-recordings are considered. The question posed by students, their typical answers the questions posed by the researcher are analysed as case studies.

\section{Data analysis}

The initial ideas of the students about energy emerges from the initial questionnaire in the CLOE lab. Responding to Q1 item, about half of the sample generates criteria to identify energy (in $40 \%$ only one criterion, in $13 \%$ two or more criterion), and few students (12\%) propose examples, as list of forms, or systems that "produces" energy as windmills, central powers.

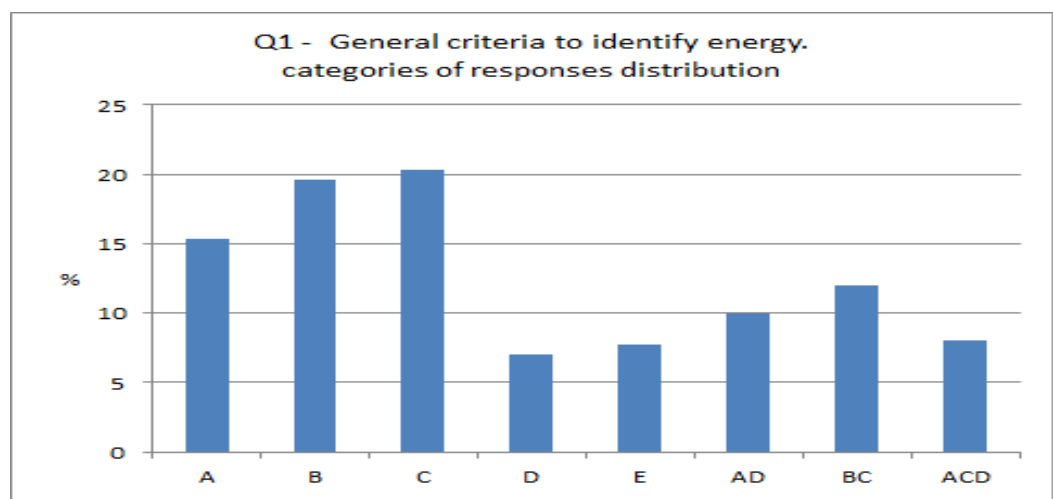

FIGURE 3. Distribution of the $\mathrm{Q} 1$ responses, in which are formulated general criteria to identify energy.

A) existence of energy in various types/forms; B) energy as a source; C) energy identified with other thing or entity; D) properties/attributes of energy; E) existence of sources of energy.

Summarizing the students conception, energy is identified, primarily, with its several forms or types (22\%). Students quoted more frequently the forms of energy without any distinction between types (kinetic, potential, internal energy and energy associated to light) and the other forms (related to the "production" of electrical energy). Energy is identified also as an entity that transforms in the processes, maintaining its identity (22\%). For a part of the students (20\%), energy is a source associated to what makes things work, what supplies mechanical or electrical apparatuses as computer and TV, what produces or is associated to movement. The idea that energy is an universal fuel $[10,13]$ should be included here. Students evidenced that they "need 
energy" for life, quoting often the movement of livings or the need of food for our life. As concern the association of energy to livings [12-13], it emerges the reference to the human body as a system that "has" energy, rather than a system that "makes" energy as sun or fuel.

Very few students (6\%) define energy as the capability to do work. Often, energy was also identified as a quantity or as an entity that is conserved and/or transformed (25\%), even if only for $1 \%$ it has a meaning consistent with the scientific one. For students conserve energy means (42\%): not use; last long/being during the process; not destroyed completely; storage in specific systems; take as an object or take away for re-use. The idea of conservation coexists usually with the largely diffused conviction that energy is lost or it disappears (20\%), or that energy is lost because is wasted (26\%). Just few students affirmed that energy is not conserved because is dispersed (about $6 \%$ ) or is exchanged between systems (5\%).

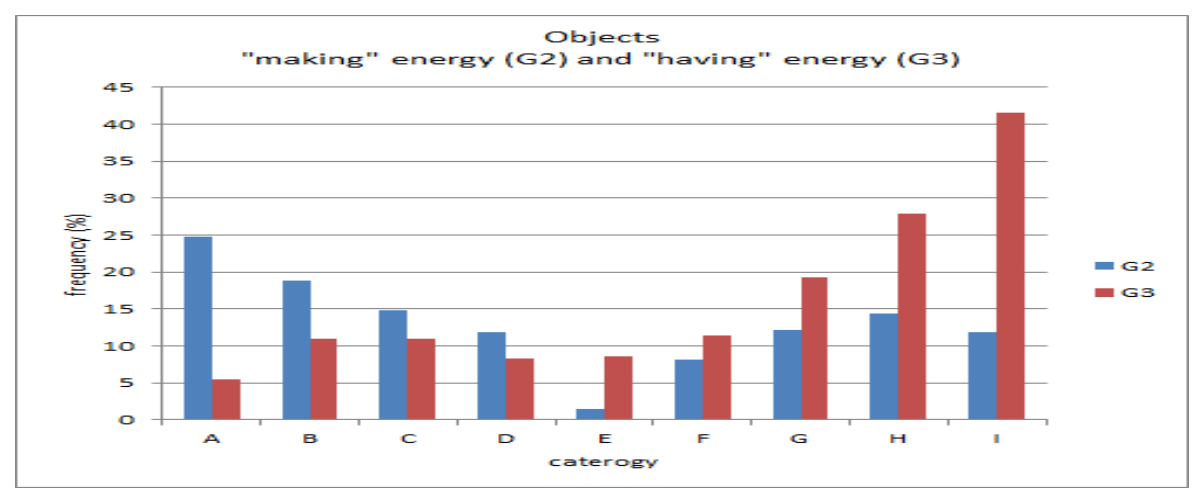

FIGURE 4. Comparison of the distributions of the category of object/systems that "make" energy (Q2 question), and "have" energy (Q3 question). Legend: A) water/air/wind; B) power central; C) sun; D) fuel; E) batteries; F) electricity, magnetism; G) Light; H) human body; I) electrical devices/motors/car.

It is quite small the number of students, arguing that energy is not lost, because it is conserved and transformed (3\%). This crucial knot concerning the concept of energy, is interlaced with the other problematic aspects related to the meaning of transformation. A part of students associating the verb transform to a change from a form of energy to another one (18\%), it is more frequent the ideas that energy transforms in $(15 \%)$ or comes from $(13 \%)$ other quantity or entity as electricity, movement, light, heat, wind or systems as food or fuel. Energy can disappear during a process, and then reappearing at the end of such a process, preserving his identity. The concept of transformation, moreover, is sometimes identified with transmission and transfer [1-3].

The discussion about answers to the different items of the questionnaire in the CLOE labs evidenced the attention of students on energy of human body, on the identification different forms. Students have been shown to perceive the importance of energy, but did not know how to treat it. For that in the second part of the CLOE labs students were engaged in the discussion of the knots emerged in the previous phase analyzing in terms of energy some specific simple situations, for instance that showed in fog. 1 . Analyzing the situation step by step the majority recognized the sub-systems involved and to associate to it a proper energy types (almost 70\%). A part of them analyzed also the process in terms of energy transformations (30-40\%).

Discussing the previous systems, students were able often to described the process in term of dispersion of energy (in the air, in the system itself...), rather than in term of energy loss. They need to reconstruct the chain of phenomena observed, by when the pass on the analysis of 
processes in terms of energy tend to refer only the net energy transformation. We can stress here that during the CLOE labs, just in episodic cases pupils uses the word "force" instead of "energy". At the end of each CLOE lab, the pupils were asked to summarize what they learned. On the whole, students expressed confidence that they could recognize falling and spring energy and knew that these could become kinetic and/or internal energy. A large majority of students associate energy to systems (more than $80 \%$ ). The initial idea of energy as an autonomous entity was often overcame, remaining in a minority of cases (less than 20\%).

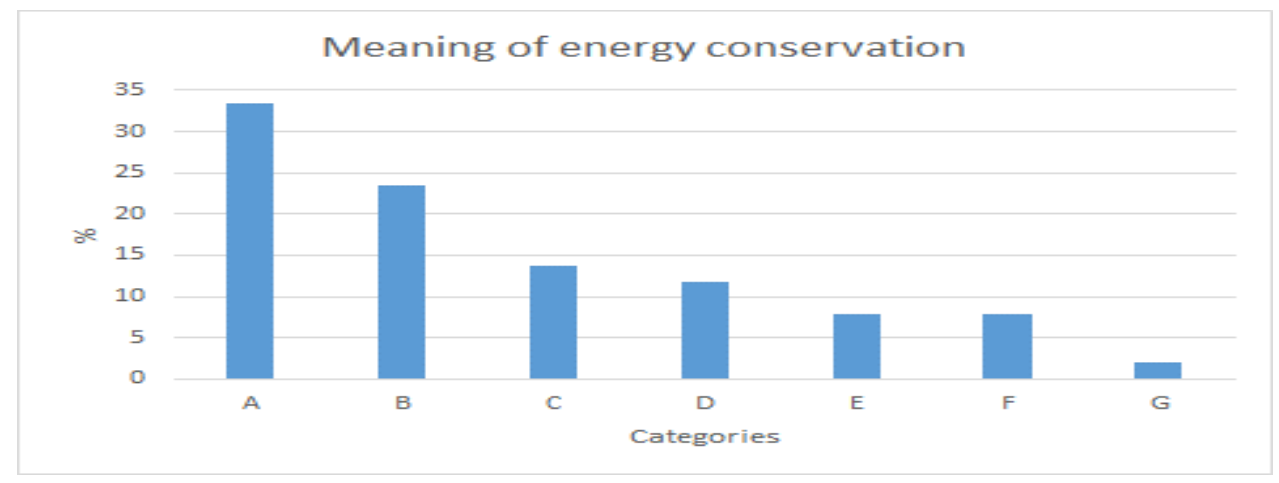

FIGURE 5. Categories of the meanings of energy conservation: A) Not used; B) last long/being during the process; C) storage; D) taking as an object; E) transform; F) never ending; G) do not change in time.

\section{Conclusions}

In a project about teaching and learning energy, a research based proposal for primary was designed. This proposal adopt an inquiry strategy and focus on the development of the types of energies having a mechanic or thermodynamics meaning (kinetic, potential, internal and associated to light) and their transformations from a type to another one. Here we have discussed the results with primary students involved in Conceptual Laboratory of Operative Exploration (CLOE) on Energy. Different monitoring tools are used to collect learning of 310 students (3-5 grades) of different primary schools from two Italian town (Udine and Crema).

Using an initial questionnaire we collected information on such issues, situations, systems and contexts that students associate more prevalently to energy. They identified prevalently energy through his forms (not categorized), as an autonomous entity that can transform, or something useful for live and society. They indicated moreover electronic devices, human body, light sources as systems that possess or have energy, and sun, central power, electric generator as systems that "make" energy (RQ1). Primary students attributed to expression like energy conservation, energy transformation meaning completely different from the scientific one, as for instance: energy transforms in other entities or things; conserve energy means "take" a part, "store energy in a body" for a successive use, do not use (R2). The hands-on/minds-on situations proposed in the CLOE labs create for the students a stimulating environment in which construct step by step the four main types of energy. Students are particularly affected by some experiments that stimulated them capability to recognize the quantities indicating the different types of changes. The analysis of data shows the role of operative environments to bridge students from their initial ideas trough a functional understanding of energy (R3). 


\section{References}

[1] R. P. Feynman, R. B. Leighton, and M. Sands, Feynman Lectures (Addison, Reading, 1963).

[2] J. W. Jewett, Energy and the confused Student I: Work, The Physics Teacher,46, 38-43 (2008).

[3] R. Millar, Teaching about energy. Dep. of Educ. Studies, (York University, York, 2005).

[4] A. Hobson, Resource Letter PSEn-1, Energy, Am. J. Phys. 75 (4) 294-308 (2007).

[5] W. Kaper, and M. Goedhart, 'Forms of energy', P.I. IJSE, 24 (1), 81-96, (2002).

[6] PS2-Physical Science II (Prentice, Englewood, 1972)

[7] A. J. Brook, and P. Wells, An approach to energy. Phys. Educ. 23, 80-85 (1988).

[8] M. Carr, and V- Kirkwood, Teaching and learning about energy, Phys. Educ. 23, 86-91 (1988)

[9] R. Trumper, Teaching about energy, J. of Curr. and Superv. 12 (1), 66-75 (1996).

[10] R. Duit, and P. Haeussler, Learning and teaching energy, in Fensham, P. et al. (Eds.), The content of science, 185-200 (The Falmer Press, London, 1994).

[11] D., Watts, Some alternative views of energy, Physics Education 18, 213-217 (1983).

[12] G. Nicholls, and J. Ogborn, Children's conceptions of energy, IJSE. 15 (1), 73-81 (1993).

[13] R. Trumper, Children's energy concepts: a cross-age study, IJSE, 13 (2) 139-148 (1993)

[14] J. Solomon, Messy, contradictory and obstinately persistent. School Scie Rev. 65, 225-229 (1983).

[15] P. Heron, Michelini, M., and Stefanel, A., Teaching and learning the concept of energy in primary school, in Constantinou, C. et al., (Univ. of Nicosia, Nicosia, 2009).

[16] H., Dahncke, R. Duit, and H. Niedderer. A hierarchy of concepts and principles, types of learning, in Frey, K. et al. (Ed.), Kognitionspsychologie und naturwissenschaftlicher, 341-365 (Huber, Bern, 1973).

[17] N. L. Tsagliotos, The concept of mechanical energy with 5th grade children, in Psillos, D. et al. (Eds.), Science Educational Research, Vol. 1, 121-124, (Univ. of Thessaloniki, Thessaloniki 2001).

[18] F. Goldberg, V. Otero, AJP 78 (12), 1265-1277 (2010).

[19] P.R.L Heron, M. Michelini, and B.S Eylon, Y. Lehavi, A. Stefanel (2014) Teaching about energy. in Teaching and Learning Physics. W. Kaminski, M. Michelini, (eds.), (Udine: Lithostampa), 2014, 284-302. [20] M., Michelini, The Learning Challenge: A Bridge between everyday experience \& scient. know., in Planinsic, G. et al. (Eds.) (GIREP, Ljubljana, 2006), 18-39.

[21] A., Stefanel, C., Moschetta, M., Michelini Cognitive Labs in an informal context, in Michelini M. et al. (eds.), Dev. Formal Thinking (Forum, UD, 2002), 276-283. 
[22] L. C. McDermott, P. S. Shaffer, C. P. Constantinou, Preparing teachers to teach physics and physical science by inquiry, Physics Education 35 (6), p. 411-416, 2000. 